\title{
ПОЛЬСКИЙ И РУССКИЙ РЫБОЛОВНЫЕ СОЦИОЛЕКТЫ (МОТИВАЦИОННЫЙ АСПЕКТ)
}

\section{Polish and Russian Angling Sociolects (Motivational Aspect)}

Keywords: sociolect, comparative analysis, angling sociolect, motivational aspect, word-formation, angling

Contact: Uniwersytet Śląskiw Katowicach; aleksandrazieba33@gmail.com

Кто и каким способом впервые поймал и приготовил рыбу - установить не удастся никому из исследователей. Однако не подлежит сомнению то, что рыболовство с древнейших времен играло существенную роль в жизни человека, влияя на профессиональную деятельность и обеспечивая людей продовольствием. Рыбная ловля имеет своим началом эпоху среднего палеолита, а в средний каменный век становится одним из видов хозяйственной деятельности - охотники применяют новые и более результативные средства, позволяющие просуществовать в тяжелых условиях мезолита ${ }^{1}$. С этого времени рыболовство постоянно усовершенствуется, считаясь значимой отраслью народного хозяйства, а главный объект ловли становится важным символом для многих культур и религий.

Наряду с рыбаками, воспринимающими ловлю как способ заработка, появились и те, для которых добыча рыб является формой проведения свободного времени, увлечением и своеобразным стилем жизни. Рыбалка для рыболова - это и отдых, и хобби, связанные с приобретением снаряжения, чтением специализированных журналов и общением с другими такими же рыболовами. Для некоторых это также вид спорта, форма туризма, основывающаяся на поиске новых водохранилищ, а также медитация на лоне природы, доставляющая эмоции и приобретение опыта ${ }^{2}$. Вместе с тем это и специфическая субкультура, характеризующаяся собственным языком, или социолектом, которому и посвящена предлагаемая статья.

\footnotetext{
${ }^{1}$ Режим доступа: https://ru.wikipedia.org/wiki/рыболовство (2020-02-29).

${ }^{2}$ Gołdowski, K. Polski socjolekt wędkarski. Kraków: Uniwersytet Jagielloński, 2013, c. 13.
} 
Социолект определяют как вариант национального языка, используемый представителями определенной социальной группы, в нашем случае таковыми являются рыболовы-любители широко понимаемой рыбалки. По замечанию Р. Токарского, рекреационный характер подобного рода деятельности находит свое отражение в языке ${ }^{3}$, что подтверждается лексическими и семантическими особенностями. В последние десятилетия наблюдается рост интереса лингвистов к изучению рыболовной лексики, о чем свидетельствуют многочисленные научные работы, словари, а также диссертации, посвященные анализу данного лексикона. Связано это также и с возникновением рыболовных журналов, сайтов и форумов, не говоря о развитии снаряжения, применяемого во время ловли. Вместе с тем до сих пор можно было бы говорить о работах, основывающихся на рыболовном социолекте одного языка. В предлагаемой статье мы предпримем попытку сравнить польскую и русскую рыболовную лексику, исходя из особенностей той и другой, сосредоточиваясь в выбранных для сопоставительного анализа единицах на их мотивационном аспекте.

Более или менее основательно рассмотреть выявляемый состав единиц задача весьма трудоемкая, что обусловлено не в последнюю очередь тем, что территориальная дифференциация существенно повлияла на формирование социолектов, обнаруживающих как отличия, так и несомненные сходства. Наличие диалектизмов, жаргонизмов, а также профессионализмов, проникающих в социолект из рыбацкой речи, не облегчает задачи. К тому же и тематических групп в данной лексике настолько много, что объем статьи не позволяет их все перечислить. В то же время анализ имеющихся польских и русских работ сделал возможным создание следующей общей классификации:

1. Рыболовов и его одежда;

2. Рыболовные техники и методы;

3. Определения, связанные с рыбалкой: 1) действия рыболова, 2) поведение рыб;

4. Удочка и ее составные части;

5. Сигнализаторы поклевки;

6. Катушка и ее составные части;

7. Крючок;

\footnotetext{
${ }^{3}$ Tokarski, R. Uwagi o gwarze wędkarskiej. Poradnik językowy. 1977 (3), s. 121.
} 


\section{8. Грузило;}

9. Приманка: 1) спиннинговые, 2) для нахлыста, 3) естественные;

10. Определения рыб: 1) по размеру, 2) по виду;

\section{1.Рыболовные аксессуары;}

\section{2. Рыболовные фразеологизмы и пословицы.}

Основой рыболовного социолекта является научно-техническая терминология, выступающая базой последующих преобразований в составе представленных тематических групп. Профессиональные наименования, однако, не содержат в себе экспрессивности, присущей большинству коммуникативных ситуаций, в которых важными являются короткие точные сообщения, команды, обмен мнениями с характерным для них стремлением к экономии средств выражения. Значительная номинативная детализация при наличии профессиональных терминов, пригодных для оценки качества, характеризирует, в частности, язык рыболовов-спортсменов ${ }^{4}$, что подтверждает сложившееся представление о неоднородности исследуемого лексического состава. Любителирыболовы приспосабливают специальную лексику к языковым тенденциям разговорной речи, в результате чего формируется своеобразный эквивалент профессиональной терминологии. Попытаемся представить наиболее выразительные черты рыболовной лексики с учетом ее состава.

1. Неологизмы. Анализируя данную группу, мы будем использовать классификацию, предложенную С. Грабясом ${ }^{5}$, который среди новых лексических элементов выделяет такие их виды: А) Структурные неологизмы - в нашем случае это лексемы типа береговушка (короткая сеть, которую можно ставить с берега шестом), фидераст (рыболов, активно занимающийся фидером, подразумевающим способ ловли), boleniarz (удильщик, предпочитающий ловлю жерехов, польск. boleń) или wobek (диминутивное определение приманки воблера). Б) Неосемантизмы, среди которых можно выделить метафоры, метонимии и эллипсисы. Примерами для первой группы могут послужить слова типа гвоздик (вид мормышки, напоминающей гвоздь) или śledź (определение мелкой щуки, сходной размером с селедкой). Метонимию можно обнаружить при

\footnotetext{
${ }^{4}$ Бочина, Т. Г., Маиков, А. З. Функционирование профессиональной лексики в дискурсе рыболововспортсменов. Филология и культура. 2014 (58/4), с. 29.

${ }^{5}$ Grabias, S. Funkcyjna klasyfikacja socjalnych wariantów języka. Język Polski. 1974 (54), s. 22-31.
} 
анализе таких лексем, как хвост (общее наименование рыбы) или korek (поплавок, изготовленный из пробки). Эллипсисы встречаются в словах типа белье 'белые черви' (используемые в качестве приманки) или kulki 'kulki zanętowe' (шарики с аттрактантом для привлечения рыбы). В) Функтивные неологизмы, т. е. заимствованные слова, сохранившие первоначальное лексическое значение. Как уже было сказано, география существенно влияет на формирование рыболовного социолекта, в результате встречаем употребление некоторых диалектизмов, типа glapa 'лещ в познанском диалекте' или неводить 'ловить рыбу сетью-неводом (Косинский район)'. Кроме того, одной из наиболее характерных черт анализируемого социолекта является наличие большого количества заимствований из английского и немецкого языков. Это прежде всего наименования методов ловли, таких, как спиннинг, или элементов снаряжения gnom (вид металлической блесны) ${ }^{6}$.

2. Фразеология. Данная группа настолько обширна, что мы решили представить самые распространенные русские и польские рыболовные фразеологизмы, не основываясь ни на каких существующих классификациях. В России большой популярностью пользуется рыболовное пожелание Ни хвоста, ни чещуи!, на которое отвечать следует так же, как и на выражение Hи пуха, ни пера! Аналогичную ситуацию встречаем при польском рыболовном пожелании Połamania kija!, возникшем на основе существующего Połamania pióra! Многие рыболовы следуют правилу Поймал - отnусти!, что подразумевает освобождение пойманной рыбы. Это фраза имеет свой польский эквивалент, заключающий в себе дополнительное фотографирование добычи, т. е. zdjęcie buzi i do wody.

3. Пословицы. Есть основания предполагать, что пословицы являются неотъемлемой частью практически каждого социолекта. Рыболовный социолект не представляет собой исключения, в нем можно найти пословицы, связанные с эффективным методом ловли, такие, как Если свежий червячок, и рыба на крючок / Czy bierze, czy nie bierze, robaki zawsze nakładaj świeże. Особое внимание уделяется изречениям, определяющим ситуацию на водоеме, типа Где щуки нет, там карась хозяин или Na wodzie łabędzie, nic z ryb nie będzie.

\footnotetext{
${ }^{6}$ Tokarski, R. Uwagi o gwarze wędkarskiej. Poradnik językowy. 1977 (3), s. 113.
} 
Предложенная очень краткая характеристика польского и русского рыболовных социолектов не представляет всего разнообразия рассматриваемого лексического состава. Мы отметили лишь наиболее важные и выразительные черты. В следующей части работы обратим внимание на мотивационные аспекты выбранных единиц. Для анализа были отобраны наиболее интересные, с нашей точки зрения, рыболовные лексемы, учитывающие сходства и различия в процессе их номинации.

\section{Названия рыб по виду}

Этот вид единиц, объединяющий определения главного объекта интереса рыболовов, не случайно является наиболее обширным и разнообразным. Существует немало, в том числе и объемных, научных работ, посвященных анализу наименований рыб. Неотъемлемой частью этой тематической группы являются регионализмы, диалектизмы, профессионализмы, а также неологизмы, созданные в основном начинающими рыболовами. Необходимо отметить, что эта группа представляет собой наибольшее количество различий в наименованиях между польским и русским социолектами, что не в последнюю очередь обусловлено географическими особенностями и отсутствием некоторых видов рыб в той либо другой стране. В нашей работе мы решили проанализировать наименования рыб, обитающих как в Польше, так и в России.

\section{Таблица № 1: Определения щуки}

\begin{tabular}{|l|l|}
\hline \multicolumn{1}{|c|}{ Польский язык } & \multicolumn{1}{|c|}{ Русский язык } \\
\hline $\begin{array}{l}\text { kaczka, krawat, krokodyl, pistolet, } \\
\text { szczupty, zębaty }\end{array}$ & $\begin{array}{l}\text { глубинка, жаба, зубастая, карандаш, } \\
\text { крокодил, хозяйка }\end{array}$ \\
\hline
\end{tabular}

В ходе исследования себя обнаружила несколько неожиданная особенность, состоящая в том, что наименование одной из наиболее распространенных хищных и пресноводных рыб характеризуется не вполне объясняемой этимологией. Существует немало противоположных гипотез, одна из которых предполагает, что щука происходит от индоевропейского слова *skeu 'острый, резать', что аргументируется хищным характером рыбы ${ }^{7}$. Возможно, что на фоне доступных этимологических предположений их более тщательный

\footnotetext{
${ }^{7}$ Карасева, Т. В., Чжэнь, Ц. Названия рыб в современном русском языке. Актуальные вопросы современной филологии и журналистики. 2009 (5), с. 20.
} 
анализ позволил бы сформулировать более или менее вероятное происхождение слова.

Есть все основания предполагать, что внешний вид рыбы является главной мотивацией для возникновения целого ряда различных названий, типа карандаш, krawat, pistolet, kaczka или жсаба. Длинная, обтекаемая и приплюснутая форма щуки легла в основу переносного значения трех первых определений. Интересно, что польские рыболовы словом ołówek (рус. карандаш) называют не щуку, а ее соседа - угря. В свою очередь, остальные примеры из нашей таблицы заключают в себе не только какую-то внешнюю черту, служащую мотивацией для конкретного определения, но и другие характеристики щуки. Польское название $\boldsymbol{k a c z k a}$ возникло не только от ассоциаций с широким уплощенным ртом рыбы (сходство с утиным клювом), но и напоминает о том, что щука способно поедать и утят.

Характеризуемая рыба встречается главным образом в заросших травой водоемах, т. наз. жабовниках, и поэтому принято ее называть ж⿻абой (не следует забывать и об аналогии с формой рта). В группу существительных с отадъективной флективной парадигмой из нашей таблицы можно зачислить лексему zębaty / зубастая. Данные определения обращают внимание на наличие острых зубов у щуки, что подтверждается в русских фольклорных сказках, использующих словосочетание щука зубастая. Если объединить перечисленные черты внешнего вида рыбы с особенностями ее поведения, то можно отметить признаки, связывающие щуку, в частности, с пресмыкающимися. Из этого следует как русском, так и в польском социолекте определение крокодил / krokodyl. В некоторых случаях наименование создается вследствие паронимии, что хорошо передается примером szczuply. Русский рыболовный социолект, в отличие от польского, характеризуется бо́льшим количеством определений рыб, связанных с местом их проживания, что иллюстрируется лексемой глубинка, подразумевающей глубинную щуку.

Определение щуки лексемой хозяйка подчеркивает ее доминирующую, можно сказать, главенствующую роль в водоеме. Поедая мелкие и незначащие виды рыб, она сохраняет экологическое равновесие, как бы «следит за порядком». Помимо функции биологического мелиоратора, мотивацией для такого наименования щуки может служить и то, что в древности она считалась демоническим хозяином вод, по причине своей несомненной хищности ${ }^{8}$.

\footnotetext{
${ }^{8}$ Бакланов, А. М. Рыболовный словарь Прикамья. Санкт-Петербург: Издательство Маматов, 2013, с. 192. 


\section{Определения удочки и ее составных частей}

Словообразовательной мотивацией для создания наименований удочки могут служить определения рыболовных техник ловли, названия производственных материалов и некоторых видов рыб, что находит свое отражение в материале.

\section{Таблица № 2: Определения удочки}

\begin{tabular}{|l|l|}
\hline \multicolumn{1}{|c|}{ Польский язык } & \multicolumn{1}{|c|}{ Русский язык } \\
\hline $\begin{array}{l}\text { karpiówka, samoróbka, splawikówka, } \\
\text { wegiel, żywcówka }\end{array}$ & $\begin{array}{l}\text { балалайка, бамбук, донка, живцовка, } \\
\text { японец }\end{array}$ \\
\hline
\end{tabular}

Польская лексема samoróbka служит для обозначения любого предмета, который кто-либо сделал самостоятельно. В большинстве случаев это наименование встречается при названиях каких-то технических объектов, в нашем материале подразумевает самостоятельно изготовленную удочку. Одной из самых распространенных и одновременно старейших рыболовных техник считается ловля на живца, подразумевающая рыбалку на хищных рыб, где в качестве наживки применяются разнообразные виды рыбок мелких и малоценных. Так снаряженную удочку принято называть жсивцовкой / żywcówka.

Продолжая тему названий удочек, возникших вследствие соединения их с методами ловли, проанализируем лексемы splawikówka и донка. В случае первого определения несложно догадаться, что мы имеем дело с удочкой, предназначенной для поплавочной рыбалки, где главный центр интереса сосредоточивается на колебании сигнализатора (поплавка) ${ }^{9}$. В свою очередь, удочка второго типа предназначена для ловли рыбы в нижних слоях воды, которую забрасывают в водохранилище и удерживают за счет веса кормушки. Ряд этих действий рыболова определяется как донная ловля, откуда и возникло наименование для данного вида снасти.

В состав разбираемой группы входят также метонимические названия, основывающиеся на связи удочки и материала, из которого она изготовлена. В данном случае речь идет о единицах wegiel и бамбук, определяющих, соответственно, удилище из углеродного волокна и бамбукового волокна. Подавляющее большинство польских названий удочек содержит в себе характерное окончание, а именно суффикс -ówk(a). Эту закономерность можно

\footnotetext{
${ }^{9}$ Gołdowski, K. Polski socjolekt wędkarski. Kraków: Uniwersytet Jagielloński, 2013, c. 37.
} 
заметить в примере из приведенной таблицы, который может подсказывать не вполне правильную мотивацию. Karpiówka - удочка, применяемая для ловли карпа, но следует подчеркнуть, что эта лексема чаще употребляется как общее название для удочек, предназначенных для ужения крупных рыб. Короткая небольшая удочка, используемая во время зимнего рыболовного отдыха, получила название одного из самых известных русских символов - балалайки. Широкий корпус снасти вызывает однозначные ассоциации с данным народным инструментом $^{10}$. В некоторых случаях страна производства удочки выступает ведущим мотивационным признаком ее наименования. Японец представляет собой спиннинговое удилище, выпущенное в Японии, а само определение воспринимается положительно, потому что снасть характеризируется высоким качеством изготовления.

\section{Определения, связанные с рыбалкой - действиями рыболова}

Подавляющее большинство единиц этой группы составляют наименования, возникшие на основе используемой приманки или рыболовного аксессуара, к этому следует добавить неосемантизмы, а также имена действий, предшествующих процессу ловли.

\section{Таблица № 3: Определения действий рыболова}

\begin{tabular}{|c|l|}
\hline \multicolumn{1}{|c|}{ Польский язык } & \multicolumn{1}{|c|}{ Русский язык } \\
\hline $\begin{array}{l}\text { blystkować, maskować, sondować, } \\
\text { umordować, zanęcić }\end{array}$ & $\begin{array}{l}\text { забагрumb, загонять, игра, обловить, } \\
\text { nростучаmь }\end{array}$ \\
\hline
\end{tabular}

Опытный любитель рыбалки не представляет себе ловли без использования разнообразных аттрактантов (польск. zanęta), т. е. искусственных или естественных препаратов, понуждающих рыбу собираться в определенном месте водоема. Чтобы повысить возможность успешного лова, сначала следует растворить соответствующую субстанцию (zanęcić) в предполагаемом месте, после чего ожидать появления рыб. Среди рыболовных приманок наиболее известна т. наз. блесна (польск. blystka), представляющая собой металлическую пластинку продолговатой формы с крючками. Некоторые конкретные действия рыболова можно определить глаголом, полученным от названия используемой искусственной насадки - blystkować. Чтобы выявить мотивацию для определения

\footnotetext{
${ }^{10}$ Бакланов, А. М. Рыболовный словарь Прикамья. Санкт-Петербург: Издательство Маматов, 2013, с. 76. 
sondować, следует уточнить, что подразумевается в корне анализируемой лексемы. Sonda - это разговорный вариант эхолота, служащего для измерения глубины тони. Тем самым, указанный перед этим глагол отмечает использование рыболовом соответствующего аксессуара. В свою очередь, в русском социолекте подобная операция рыболова передается лексемой простучать. А это обозначает, что производитель данного действия исследует дно водохранилища, используя джиг-приманку или грузило без крючка для определения рельефа. Ощущаемый при этом стук послужил мотивационной основой отмеченного глагола.

В рассматриваемый состав следует отнести также определения, связанные с предшествующей подготовкой к ловле. Так, лексема maskować используется для обозначения маскировки элемента снаряжения таким образом, чтобы уподобить его естественной рыбам среде. Имеются при этом в виду не только рыболовные снасти, но и одежда и всевозможные второстепенные аксессуары, облегчающие процесс рыболовства.

К еще одному определению, а именно глаголу umordować, можно подобрать дефиницию 'сохраняя неослабный контакт с подцепленной на удочку рыбой, вывести ее с места подсечки на поверхность воды таким образом, чтобы не повредить снаряжения'. Главная цель подобного действия заключается в максимальном утомлении рыбы, что позволяет свободно и безопасно подсечь добычу, после чего подвести ее к берегу.

Следующий пример из таблицы содержит в себе два значения, необходимо при этом добавить, что первая дефиниция считается более распространенной. Глагол обловить образован от лексемы облов, подразумевающей ловлю рыбы по всему пространству данного водоема. Для большей эффективности клева рыболов прочесывает воду, часто меняя место заброса удочки. Этим словом также определяют ситуацию, в которой удильщик поймал больше добычи, чем его коллега, но, как мы уже сказали, такое контекстное окружение обладает меньшой употребительностью. Для увеличения лова рыбу можно также загонять, и это один из способов рыбалки, при котором рыболов пугает рыбу, направляя ее в ловушку. Инструментами, применяемыми для этой запрещенной техники, могут служить болты (издают глухой звук), боталь (длинный шест с пластиковой бутылкой на конце, которым ударяют по поверхности воды) и другие браконьерские средства. В свою очередь, багор представляет собой длинный шест с металлическим острием, заканчивающийся большим крючком. Этот рыболовный аксессуар послужил основой для создания еще одного примера из приведенной таблицы - забагрить. С помощью упомянутого инструмента можно 
подбагривать рыбу при ее вываживании, но дефиниция рассматриваемого глагола несколько иная - 'подцепить крючком рыбу не в рот, а за плавник, хвост или тело’.

В приведенной таблице, помимо названий конкретных действий, встречается гипероним, анализ которого обнаруживает целый ряд посторонних способов ловли. Речь идет о единице игра, подразумевающей комплекс действий, предпринимаемых удильщиком в процессе проводки, главная задача которых состоит в придании движению приманки естественности. Этот способ характеризуется большой эффективностью, поскольку рыба часто смешивает наживку с перемещением мелких живых существ.

Проделанный анализ подтверждает представления о том, что рыболовная лексика может стать интересным материалом, требующим пристального внимания лингвистов. Данный состав единиц представляет собой неограниченное разнообразие лексем и фразеологизмов, подробный анализ которых позволит обнаружить закономерности формирования польского и русского социолектов. Процессы глобализации, международные рыболовные соревнования привели к тому, что в настоящее время наблюдается больше сходств, чем различий в употреблении данного типа лексики. Однако внимательное изучение рыболовных социолектов способно выявить не только сходства, но и вполне очевидные несовпадения и различия, что позволит сделать в дальнейшем исследования более точными и основательными. В ходе анализа себя обнаружило существенное отсутствие российских работ, посвященных рыболовной лексике. Их место занимают словари, учитывающие рыбацкую специальную лексику, без учета при этом языка рыболовов-любителей. Факт этот также должен учитываться при подборе лексики для лингвистов, занимающихся изучением русского рыболовного социолекта.

\section{Summary}

The aim of the article is to present the underestimated abundance of Polish and Russian angling vocabulary. Because of the entertaining character of the activity, this scientific material is not that much appreciated among the linguists. The analysed words were divided by the specified categories, which occur in the others theses related to this subject. There are observed similarities in the Polish and Russian terminology and some differences that occur due to territorial and cultural diversity. It is especially visible in the fish nomenclature. It is determinated by some subdialects. In most cases the analysis revealed the same word-formation base of the linguistic units and the similar way 
sociolects form. The research material includes some words reported in the specialized dictionaries and on the websites dedicated to angling.

\section{Литература}

Бакланов, А. М. Рыболовный словарь Прикамья. Санкт-Петербург: Издательство Маматов, 2013.

Бочина, Т. Г., Маиков, А. 3. Функционирование профессиональной лексики в дискурсе рыболовов-спортсменов. Филология и культура. 2014 (58/4), c. $29-33$.

Карасева, Т. В., Чжэнь, Ц. Названия рыб в современном русском языке. Актуальные вопросы современной филологии и журналистики. 2009 (5), c. 23-31.

Клыков, А. А. Краткий словарь рыљаџких слов. Москва: Издательство Пищевая промышленность, 1968.

Халюков, Ю. В. Лексика орловских рыбаков. Автореферат диссертаџии на соискание ученой степени кандидата филологических наук. Орел: Орловский государственный университет, 2008.

Bajerowa, I. Badania nad terminologią języków specjalnych ('środowiskowych). In: Rieger, J., Szymczak, M. (eds.) Język polski i językoznawstwo polskie w sześćdziesięcioleciu niepodległości. Wrocław: Zakład Narodowy im. Ossolińskich, 1982, s. 37-40.

Fenczyn, J. Wędkarstwo jako czynność rekreacyjna. Kraków: Akademia Wychowania Fizycznego im. Bronisława Czecha, 1998.

Grabias, S. Funkcyjna klasyfikacja socjalnych wariantów języka. Język Polski. 1974 (54), s. 22-31.

Gołdowski, K. Polski socjolekt wędkarski. Kraków: Uniwersytet Jagieloński, 2013.

Kowalska, A. Jeszcze o nazwach szczupaka w północno-wschodnich gwarach Polski. Poradnik Jezzkkowy. 1961 (1), s. 24-28.

Tokarski, R. Uwagi o gwarze wędkarskiej. Poradnik językowy. 1977 (3), s. 111-121.

\section{Интернет-источники}

Режим доступа: https://ru.wikipedia.org/wiki/рыболовство (29-02-2020). 